\title{
Macro-economic Models: How to Spend Uganda's Expected Oil Revenues? A CGE Analysis of the Agricultural and Poverty Impacts of Spending Options
}

\author{
Manfred Wiebelt, Karl Pauw, John Mary Matovu, Everist Twimukye, \\ and Todd Benson
}

\section{Introduction}

With the recent discovery of crude oil reserves along the Albertine Rift, Uganda is set to establish itself as an oil producer in the coming decade. Total oil reserves are believed to be two billion barrels, with recoverable reserves estimated at $0.8-1.2$ billion barrels. This is comparable to the level of oil reserves in African countries such as Chad (0.9 billion barrels), Republic of the Congo (1.9 billion barrels), and Equatorial Guinea (1.7 billion barrels) but far short of Angola (13.5 billion) and Nigeria (36.2 billion) (World Bank 2010). Using a conservative reserve scenario of 800 million barrels, peak production, likely to be reached by 2017 , is estimated by

\footnotetext{
This contribution heavily draws on IFPRI Discussion Paper 1122. The underlying research was financially supported by the Uganda office of the Department for International Development (DFID) of the Government of the United Kingdom through their support to the International Food Policy Research Institute under the Uganda Agricultural Strategy Support Program (UASSP) project. The authors wish to thank participants of two workshops held in Kampala on November 25, 2010 and in Kiel on July 2-3, 2011 for their valuable comments and suggestions for improvement.
}

M. Wiebelt $(\bowtie)$

Kiel Institute for the World Economy, Kiel, Germany

e-mail: Manfred.wiebelt@ifw-kiel.de

K. Pauw

Food and Agriculture Organization, Addis Ababa, Ethiopia

J.M. Matovu

Research for Transformation and Development, Kampala, Uganda

E. Twimukye

Economic Policy Research Centre, Kampala, Uganda

T. Benson

International Food Policy Research Institute, Washington, DC, USA

C. Henning et al. (eds.), Development Policies and Policy Processes in Africa,

Advances in African Economic, Social and Political Development,

DOI 10.1007/978-3-319-60714-6_3 
the World Bank to range from 120,000 to 140,000 barrels per day, with a production period spanning 30 years. A more optimistic scenario in this study is based on 1.2 billion barrels and sets peak production at 210,000 barrels per day (see Wiebelt et al. 2011). Although final stipulations of the revenue sharing agreements with oil producers are not yet known, government revenue from oil will be substantial. One estimate, based on an average oil price of US\$75 per barrel, puts revenues at approximately 10-15\% of GDP at peak production (World Bank 2010). The discovery of crude oil therefore has the potential to provide significant stimulus to the Ugandan economy and to enable it to better address its development objectives, provided oil revenues are managed in an appropriate manner.

If the experience of other resource-abundant countries is anything to go by, the prospects are alarming. Cross-country evidence suggests that resource-abundant countries lag behind comparable countries in terms of real GDP growth (Sachs and Warner 1995, 2001; Gelb 1988; IMF 2003); that the negative relationship between resource abundance and economic growth is stronger for oil, minerals, and other point-source resources than for agriculture; and that this relationship is remarkably robust (Sala-i-Martin and Subramanian 2003; Stevens 2003). Nonetheless, several countries have managed to avoid this so-called resource curse. Indonesia's economy grew by an average of 4\% per year during 1965-1990, while oil and gas exports rose quickly in the 1970s, reaching 50\% of exports in the early 1980s (Bevan et al. 1999). Botswana achieved double-digit growth in the 1970s and 1980s despite rapidly growing diamond exports since the 1970s, and this development occurred despite the enclave character of the mineral industry (that is, low backward and forward linkages to other sectors) (Acemoglu et al. 2003). Other resource-rich countries, such as Malaysia, Australia, and Norway, have successfully diversified their production structures, laying the ground for broad-based balanced growth.

The anxiety about the effects of resource booms partly reflects reservations about the absorptive and managerial capacity of public sectors-particularly in developing countries - to manage large-scale investment programs or to rapidly step up service delivery without a loss in quality. In part, it also reflects even deeper reservations about resource dependency and the impact of windfall profits on the domestic political economy (Ross 2001; Leite and Weidmann 1999; Easterly 2001). However, more traditional concerns about the macroeconomics of resource booms also figure large, and these are the focus in this study. Dominating these concerns is the fear that the additional foreign exchange arising from the exploitation and exportation of natural resources may cause an appreciation of the real exchange rate. Although a strong domestic currency is good news for importers, Rodrik (2003) warns of the danger an uncompetitive real exchange rate holds for overall economic growth and development. The subsequent loss of competitiveness in the nonresource tradable goods sectors-or Dutch Disease - may hamper growth in traditional export sectors such as manufacturing or agriculture. These sectors are often major employers in developing countries and serve as the engines of growth. Of course, exportation of natural resources does not inevitably have negative consequences for the economy; for example, if the resource flow emanating from the newly exploited natural resource is small relative to overall trade flows, or there are underemployed factors of production that can be used in the expanding natural resource exploitation sectors with little opportunity cost, 
or both, an expansion in natural resource exports will not necessarily lead to Dutch Disease (see Hausmann and Rigobon 2002; Sala-i-Martin and Subramanian 2003).

This study considers the impact of crude oil extraction and exportation on the Ugandan economy with a specific focus on how it might affect the agricultural sector. We also consider various options open to the Ugandan government for saving, spending, or investing forecasted oil revenues over the coming three decades. For this analysis we modify a recursive-dynamic computable general equilibrium (CGE) model of Uganda by including crude oil extraction and refining industries. These industries are allowed to grow and shrink over time in line with the forecasted oil production trend, while oil revenues accruing to government are either saved abroad in an oil fund (this sterilizes the exchange rate effect) or spent domestically. Several spending scenarios consider the effects of using the balance of oil funds (that is, after deducting amounts saved) to develop public infrastructure. Here we consider scenarios where infrastructure investments only contribute to long-term growth through raising productive capacity, or where they also have productivity spillover effects in targeted sectors (for example, in agricultural or nonagricultural sectors specifically). Scenarios where oil revenues are distributed to citizens in the form of household welfare transfers or used to subsidize prices (for example, fuel subsidies) are also modeled.

The contribution is structured as follows. We first provide an overview on spending options. Particular attention is given to infrastructural investments and their effects in developing countries. Next, we introduce the CGE model and describes the simulation setup and design, then present and discuss the model results. Last, we draw conclusions.

\section{Investing Oil Revenues: Options and Challenges}

For the past two decades Uganda has managed its public finances and the macro economy in a prudent manner, yet the prospect of a large influx of oil revenue presents a major challenge to government. Even though Uganda's oil reserves are not massive compared to those of the major oil producers of the world, the expected revenue is still substantial relative to the current size of the economy.

There are at least three dimensions to the oil revenue spending challenge that lies ahead: First, there is the issue of how to manage oil price volatility. Volatile prices imply volatile revenue flows from one year to the next, which makes long-term planning difficult. Second, while increased administrative capacity will be required to manage a much larger infrastructural and social spending budget, the danger exists that government becomes too large and undisciplined in its spending. If service delivery becomes inefficient and administrative expenditures (for example, on salaries) grow too much there will ultimately be less funding available for all-important infrastructural spending. Third, infrastructural spending itself may be inefficient due to a lack of administrative or absorptive capacity within government. While spending will contribute to GDP in the current period, thus creating the perception of growth, it may not translate into increased production capacity and higher levels of productivity in future periods, which ultimately hampers the sustainability of oil revenue spending. 


\subsection{Revenue Stabilization Options}

One way to deal with revenue volatility and concerns about spending inefficiency is to transfer oil revenues into a foreign "oil fund" from which a smaller or a more stable revenue flow is extracted. The first option is to set up a budget stabilization fund (SF), which involves allocating a certain share of government oil revenues to a fund that can be tapped when low oil prices cause revenues to drop below projected flows. Examples include the SF of the Russian Federation or the State Oil Fund in Azerbaijan. When using an SF government may still plan to spend all oil revenues during the oil extraction period, in which case the SF is only used to smooth the revenue flow as it deviates from projected revenues. However, such a fund could also be used to extend the spending period beyond the oil extraction period by saving a greater share of annual revenue and continuing to draw on accrued savings that remain at the end of the oil extraction period. A second option is a permanent income fund (PIF) or heritage fund. Here all revenue from oil is transferred to the fund and only the interest earned on accumulated funds is allocated to the government budget. The Norwegian Government Pension Fund and the Kuwaiti Future Generations Fund are good examples of such PIFs. A PIF provides a much smaller flow of revenue compared to the default option of spending all revenues immediately, but the income stream is perpetual, thus having the potential of benefiting future generations. The revenue stream is also likely to be fairly stable or predictable, especially when long-term fixed interest rates are earned on the accumulated funds.

Although the development challenges loom large in Uganda, a prudent spending approach is desirable. This means not succumbing to the temptation of spending too much too soon. Proponents of a spend-all approach may appeal more to the masses, with arguments that the country cannot afford to hoard revenue amidst crumbling infrastructure and developmental backlogs. However, ideally speaking, spending levels should only gradually increase in line with the pace at which government capacity grows. Uganda has taken advice of this nature on board in announcing that an oil fund will indeed be set up and managed by the Central Bank (see Uganda, Ministry of Energy and Mineral Development 2008). The way in which the fund is managed (that is, how funds are deposited or withdrawn over time) should be explicitly governed by the legal and regulatory framework for oil revenue. Such a framework, combined with a gradually enhanced institutional capacity, should cushion the country from pressure from those who would want to see quick but unsustainable gains from oil.

\subsection{Investment Spending Options}

\subsubsection{Investment for Economic Growth and Poverty Reduction}

The pace at which public infrastructure is developed is an important determinant of the development process. Numerous studies highlight the importance of the stock of 
public infrastructure as one necessary ingredient for agricultural productivity growth (Binswanger et al. 1993; Ram 1996; Esfahani and Ramirez 2002). Hulten (1996) argues it is not only the level of public investment that matters, but also the spending efficiency and the effectiveness with which existing capital stocks are used by citizens (see also Calderón and Servén 2005, 2008; Reinikka and Svensson 2002). Microeconomic studies tend to focus more on the latter aspect, and show that improved access to public infrastructure positively influences the adoption of productivity-enhancing technologies by farm households or firms (Antle 1984; Ahmed and Hossain 1990; Renkow et al. 2004). Access to and utilization of public infrastructure also has important welfare effects, including the reduction of rural poverty (Fan et al. 2000; Fan and Zhang 2008; Gibson and Rozelle 2003) and rural inequality (Calderón and Servén 2005; Fan et al. 2003). The strength of these welfare effects, however, depends on the institutional setup in countries (Duflo and Pande 2007), while strong complementarities exist between physical and human capital (Canning and Bennathan 1999). The latter suggests that investments in education, training, or rural extension services would enhance the effectiveness of infrastructural investments.

The overwhelming message is that infrastructural investments matter for development, especially when measures are in place to improve access to that infrastructure. However, it is less clear precisely where to invest in order to maximize growth and poverty outcomes. The agricultural sector stands out as a strong candidate. Agriculture is an important sector in many developing countries in terms of its share of national GDP and employment. Agricultural growth is therefore particularly important in determining the pace of poverty reduction (Diao et al. 2010; Valdés and Foster 2010). In Uganda the agricultural sector is relatively small, contributing less than one-third to national GDP. However, it remains a significant employer, with $81 \%$ of the population living in households that are directly involved in agricultural activities (see Benin et al. 2008). Farming is by no means exclusively a rural activity in Uganda (27.8\% of urban households are engaged in agricultural activities), but it is clear from population statistics that a focus on rural agriculture is warranted: 9 in 10 farm households live in rural areas, and one in three rural inhabitants are poor, compared to $13.8 \%$ of urban people. This implies that growth in the agricultural sector has the potential to significantly reduce poverty in Uganda. Weak historical agricultural growth, low agricultural yields, and poor infrastructure in Uganda all point to the great potential for this sector to grow rapidly should significant public investments, particularly in infrastructure, reach this sector.

Using a recursive-dynamic CGE model, Benin et al. (2008) are able to demonstrate how rapid agricultural growth achieved through yield improvements under the Comprehensive Africa Agricultural Development Programme (CAADP) in Uganda contributes to overall growth and poverty reduction. CAADP aims to achieve $6 \%$ agricultural growth by committing countries to allocate $10 \%$ of their overall budgets to the agricultural sector in the form of infrastructure investments, research and development, and extension services. In Uganda the 6\% growth target implies a doubling of the agricultural growth rate, which, historically, has remained at just below 3\%. Benin et al. (2008) show that if agricultural growth is maintained at $6 \%$ over the period 2005-2015, the national GDP growth rate in Uganda will 
increase by $1 \%$ point (that is, from 5.1 to $6.1 \%$ ). Agricultural growth also has spillover effects into the rest of the economy, with agroprocessing or foodprocessing and trade and transport sectors benefiting from more rapid growth. More importantly, however, are the poverty-reducing effects of rapid agricultural growth. Benin et al. (2008) show that under an accelerated agricultural growth path the poverty rate in 2015 will be $7.6 \%$ points lower than the forecasted level under the business as usual growth path. This is equivalent to an additional 2.9 million people being lifted out of poverty by 2015 .

Benin et al. (2008) extend their analysis to focus on specific agricultural subsectors' effectiveness at reducing poverty and generating growth through size and economic linkage effects. In this regard they find that horticultural crops, root crops, livestock, and cereals have the greatest poverty-reducing potential in Uganda. This is due both to the crop choices of resource-poor farmers and to the preferences of poor consumers (increased productivity lowers farmers' unit production costs and benefits consumers via price reductions). Given their initial size, growth potential, and economic linkages, growth in subsectors such as roots, matooke (cooking banana), pulses and oilseeds, and export crops contribute most to overall growth.

Using a similar methodology, Dorosh and Thurlow (2009) focus more closely on the relative impacts of rural versus urban public investments in Uganda. In general, they find that improving agricultural productivity generates more broad-based welfare improvements in both rural and urban areas than investing in the capital city, Kampala. Although investing in Kampala accelerates economic growth, it has little effect on other regions' welfare because of the city's weak regional growth linkages and small migration effects. In a study in Peru, Thurlow et al. (2008) find that by investing in the leading (more urbanized) region, that country may be undermining the economy in the lagging (mostly rural) region by increasing import competition and internal migration. The authors also show that the divergence between the leading and lagging regions can only be bridged by investing in the lagging region's productivity through providing extension services and improved rural roads.

This brief overview suggests that public investments in rural areas and agriculture should be a critical part of the development strategy in Uganda if the country is to achieve its goals of reducing (rural) poverty and narrowing the welfare gap between urban and rural areas. Studies cited show that investments in cities or major urban centers such as Kampala, although good for growth there, may in fact be harmful or at best neutral for growth or welfare in rural areas. Either way, such investments will lead to rising rural-urban inequality, which is an undesirable socioeconomic outcome. The challenge is to be strategic about how and where to invest so that productivity gains in priority sectors or subsectors are maximized. Certain types of investments have obvious impacts; for example, investments in rural roads, irrigation infrastructure, or water storage will benefit agriculture, and depending on the exact location (or agronomic zone) of those investments, specific subsectors within agriculture. For other types of investments, such as telecommunications, it is likely that urban-based manufacturing sectors would benefit more, but there may still be intended or unintended productivity spillovers into other 
sectors. It is also important to realize that there may be a lag from the time the investment in agriculture is made until productivity spillovers materialize and rural poverty declines. The immediate beneficiaries of increased agricultural investment spending are more likely to be those nonpoor workers supplying investment services or producing investment goods rather than poor farming households themselves.

\subsubsection{Transferring Rents to Citizens}

The massive infrastructural spending backlogs in Uganda mean much of the policy discussion around spending of oil revenue has and will continue to focus on public investments. However, infrastructural spending is not the only option open to government. Some argue that oil revenues should be spent on the provisioning of social protection: Since citizens in effect own the oil resource, the most appropriate approach is to transfer revenues back to them. Social protection can be broadly defined. Benefits transferred to citizens can be in the form of tax breaks (for example, income or consumption tax cuts); subsidies (for example, direct price subsidies, employment subsidies, or investment subsidies); job creation schemes; or direct transfers (Gelb and Grasmann 2010). Not all these transfer mechanisms necessarily involve a direct transfer from government to households; some work indirectly via employment or consumption.

Gelb and Grasmann (2010, 12-16) briefly review the merits of and justification for each of these benefits while Gelb and Majerowicz (2011) consider the strengths and limitations of cash transfers in Uganda. A lower tax burden, they explain, might reduce the deadweight costs of taxation, provided the quality of tax administration does not decline at the same time. Lower taxes, in general, will encourage economic activity, thus compensating export sectors in particular for the adverse effect of a stronger exchange rate. Domestic price subsidies are popular for obvious reasons. A common type of subsidy in oil-producing economies is one on petroleum products; in fact, in many countries petroleum prices are kept far below market levels at a subsidy cost equivalent to "several percentage points of GDP" (Gelb and Grasmann 2010, 13). An approach that is used "more widely in the Middle East than elsewhere" (Gelb and Grasmann 2010, 14) is public-sector job creation. One estimate suggests that around $80 \%$ of jobs in Gulf are in the public sector (for example, in Kuwait, employment for nationals is virtually guaranteed).

Very few countries have considered the use of oil revenues to finance direct welfare transfers. However, there is increasing interest in distribution mechanisms such as those pioneered in Alaska "as the shortcomings of other approaches become more apparent" (Gelb and Grasmann 2010, 14). Cash transfers or grants have two primary functions: They reduce short-term poverty and inequality, and they provide safety nets that enable households to manage risk (Pauw and Mncube 2007). There are several design options. First, grants can be targeted or universal. Targeted grants are more costly to administer, but targeting improves efficiency in terms of reductions in poverty and inequality. Under a universal grant scheme all citizens have 
access to a grant, irrespective of their socioeconomic status. Second, grants can be conditional or unconditional. Conditional grants, as the name suggests, are only accessible by households that comply with certain provisions, such as attending school or visiting health clinics.

The successes of conditional programs such as Bolsa Familia in Brazil and Opportunidades in Mexico have been widely reported (see, for example, Adato and Hoddinott 2010). However, just like targeting, conditionality increases the administrative burden of these programs, both for administrators who need to determine eligibility of prospective participants and for health and education service providers who need to deal with the mandatory increase in demand for these services. For this reason conditionality may not always be a good idea, especially in countries where administrative capacity is low or where social service delivery is weak (Pauw and Mncube 2007). The alternative (that is, a nontargeted unconditional grant scheme) is costly, but the large influx of oil revenues in Uganda puts the country in a position where it can probably afford such a basic income grant. Although a uniformly distributed grant will not improve inequality, it will reduce poverty, while at the same time policymakers can avoid sensitivities that may arise when oil revenues_-seen by all as a national resource - are unequally distributed.

\section{CGE Model Simulation Setup}

\subsection{The Ugandan Recursive-Dynamic CGE Model}

This study applies a single-country recursive-dynamic CGE for Uganda (also used by Benin et al. 2008) to investigate the effects of oil production and to consider alternative options for spending oil revenue. This modeling tool is useful as it captures the important direct and indirect effects associated with oil production and the spending of oil revenues. In a similar study to this one, Breisinger et al. (2009) also use a CGE model to examine the potential trade-offs between spending and saving of oil revenues in Ghana. The CGE model is a member of the class of single country neoclassical CGE models first developed by Dervis et al. (1982) and features endogenous prices, market clearing, and imperfect substitution between domestic and foreign goods. Below we highlight some of the key features of the Ugandan model. A detailed model description and equation listing can be found in Thurlow (2004).

\subsubsection{Private Production and Consumption}

Producers and consumers in the model are assumed to enjoy no market power in world markets, so the terms of trade are independent of domestic policy choices. 
Firms in each of the 52 economic sectors (or activities) are assumed to be perfectly competitive, producing a single good that can be sold to either the domestic or the export market. Production in each sector $i$ is determined by a constant elasticity of substitution (CES) production function of the form.

$$
Q_{i}=A_{i} \Sigma_{f}\left\{\delta_{f i} F_{f i}-\rho i\right\}^{-1 / \rho i},
$$

where $f$ is a set of factors consisting of land, cattle, capital, and different labor categories; $Q_{i}$ is the sectoral activity level; $A_{i}$ the sectoral total factor productivity; $F_{f i}$ the quantity of factor $f$ demanded from sector $i$; and $\delta_{f i}$ and $\rho_{f i}$ are the distributional and elasticity parameters of the CES production function, respectively. Only agricultural crop production requires land. Sectoral supply growth of land is fixed. Sector capital endowments are fixed in each period but evolve over time through depreciation and investment. Capital and labor markets are competitive so that these factors are employed in each sector up to the point that they are paid the value of their marginal product. Private-sector output is also determined by the level of infrastructure, which is provided costless by the government. We assume that total sector factor productivity $A_{i}$ depends on the availability of public infrastructure.

Consumption for each household type is defined by a constant elasticity of substitution linear expenditure system, which allows for the income elasticity of demand for different goods to deviate from unity. The CGE model endogenously estimates the impact of alternative growth paths on the incomes of various household groups. These household groups include farm and nonfarm households and are disaggregated across rural areas, the major city of Kampala, and other smaller urban centers. Each of the households questioned in the 2005/06 Uganda National Household Survey (UNHS5) are linked directly to their corresponding representative household in the CGE model. This is the microsimulation component of the Ugandan model. Changes in representative households' consumption and prices in the CGE model are passed down to the corresponding households in the survey, where standard poverty measures and changes in poverty are calculated.

\subsubsection{Macroeconomic Closures and Dynamics}

The model has a neoclassical closure in which total private investment is constrained by total savings net of public investment. Household savings propensities are exogenous. This rule implies that any shortfall in government savings relative to the cost of government capital formation, net of exogenous foreign savings, directly crowds out private investment. Likewise, any excess of government savings directly crowds in private investment.

The model has a simple recursive-dynamic structure. Each solution run tracks the economy over 40 periods. Each period may be thought of as a fiscal year (that is, from year 2007 to 2046). Within-year capital stocks are fixed, and the model is solved given the parameters of the experiment (for example, exogenous growth in 
the oil production or refining sector, or changes in import tariffs on fuels). This solution defines a new vector of prices and quantities for the economy, including the level of public- and private-sector investment, which feed into the equations of motion for sectoral capital stocks. The equation is specified as

$$
K_{i, t}=K_{i, t-1}\left(1-\mu_{i}\right)+\Delta K_{i, t-1},
$$

where $K_{i, t}$ is the capital stock, $\mu_{i}$ denotes the sector-specific rate of depreciation, and $t-1$ measures the gestation lag on investment.

The final element is an externality resulting from public investment in infrastructure. Public investment is assumed to generate an improvement in total factor productivity. Specifically, equation (1) assumes that $\mathrm{A}_{i, t}=\mathrm{A}_{i}$ for nonspillover sectors, whereas in the spillover sectors, denoted $s$, total factor productivities evolve according to

$$
\mathrm{A}_{\mathrm{s}, \mathrm{t}}=\mathrm{A}_{\mathrm{s}} \cdot \Pi_{\mathrm{g}}\left\{\left(\mathrm{I}_{\mathrm{t}}^{\mathrm{g}} / \mathrm{I}_{0}^{\mathrm{g}}\right) /\left(\mathrm{Q}_{\mathrm{s}, \mathrm{t}} / \mathrm{Q}_{\mathrm{s}, 0}\right)\right\}_{\mathrm{sg}}^{\rho},
$$

where $g$ denotes a set of public investments defined over rural and urban infrastructure, health and education, and so on; $I^{g}$ and $Q_{s}$ are real government investment and sectoral output levels; and $I^{g}{ }_{0}$ and $Q_{s, 0}$ are the correspondingly defined public investments and output levels in the base period. The terms $\rho_{\mathrm{sg}}$ measure the extent of the spillovers. If $\rho_{s g}=0$, there is no spillover from public investment in infrastructure or health and education. The higher $\rho_{s g}$, the higher are spillovers.

The total population, workforce, area of arable land, number of livestock, and income from abroad are examples of other variables that evolve over time according to exogenously defined assumptions. The growing population generates a higher level of consumption demand and therefore raises the supernumerary income level of household consumption within the linear expenditure system (LES) specific to each household and subject to the constraints of available income and the consumer price vector. Labor, land, cattle, and foreign capital supply are updated exogenously.

\subsection{Simulation Setup}

\subsubsection{Baseline Scenario}

The baseline scenario serves as the counterfactual against which other scenario results are compared. Scenarios are solved over the period 2007-2046, which roughly coincides with the forecasted crude oil extraction period. The baseline (simulation name BASELINE) is a no oil scenario, which assumes a continuation of the business as usual growth path for Uganda over the coming decades (that is, without the establishment of crude oil extraction and refining industries). Growth rates for total factor productivity, factor supply, foreign capital inflow, and real 
government consumption follow recent historical trends or are set at levels such that GDP at factor cost is targeted to grow at an annual average rate of 5.1\% until 2046 (see Table 2: Part A). The table further provides a breakdown of this growth into its different components. Absorption, which includes private consumption (5\%), investment expenditure $(4.4 \%$ ), and government expenditure (exogenously set to grow at $3 \%$ ), grows at $4.7 \%$ per year. Export growth outpaces import growth, mainly due to domestic factor productivity growth, which makes exporters more competitive in international markets. The result is a declining trade deficit, while the exogenously imposed 3\% growth in foreign capital inflows causes the real exchange rate to appreciate on average by $0.9 \%$ per year.

The results in BASELINE reveal the so-called Balassa-Samuelson effect, where tradable sectors with higher than average productivity increases and lower income elasticities of demand grow less than nontradable sectors, such as services. Thus, as expected under this growth scenario, the economic structure will continue to change in favor of services and industry. Table 2 (Part B) shows that the share of the agricultural sector in total GDP decreases from $22.6 \%$ in 2007 to $15.8 \%$ in 2046 , which is a result of a relative decline in agricultural prices driven primarily by relatively lower domestic demand for agricultural products and domestic terms of trade effects, which cause an appreciation in the real exchange rate. In contrast, the services sector continues to expand, contributing 62.5\% of GDP by 2046.

\subsubsection{Modeling Oil Production and Refining}

Several oil production and refining scenarios are modeled. All involve the same fairly rapid growth path for oil production. Growth is fastest between 2007 and 2017 when peak oil production is reached. Peak production levels are then maintained for about a decade, before production is gradually phased out over the next two decades until recoverable reserves are exhausted by 2046 . The expansion is simulated by exogenously raising or lowering the level capital stock available to the crude oil refining sector. The implicit assumption is that capital stock expansion is funded (almost) entirely by foreign direct investment. However, although the decision to invest is made exogenously by foreign investors, the oil sector still has to compete with other sectors for intermediate inputs and, to a much lesser extent, for labor resources. Furthermore, depending on how government spends its oil revenue (for example, government may spend more on public infrastructure or government services), the demand for labor will rise rapidly in those sectors required to satisfy government demand (for example, suppliers of machinery and equipment, construction services, or public service providers). All crude oil is supplied to the refining sector. Supply bottlenecks are avoided by applying a similar capital stock growth rate to the refining sector as the one that determines crude oil production levels.

Profits — or returns to capital stock — generated in the oil production and refining sectors are shared between the foreign owners of capital (their share is repatriated) and the Ugandan government (revenue is transferred via a $74.4 \%$ tax on returns to capital). All crude oil is supplied to the oil refineries, and for the sake of simplicity 
all refined oil is assumed to be exported. Domestic demand for petroleum products is, in turn, met by imports. In reality, some of the refined oil product will be retained for domestic consumption and the country will cease to import petroleum products, but modeling it in this manner is simpler and does not affect results since the balance of payments effect is symmetrical.

\subsubsection{Oil Simulation Experiments}

In all the oil simulations, oil production and refining capacity is increased and then gradually phased out to replicate the forecasted production path, which assumes peak production of about 210,000 barrels of oil per day between 2017 and 2025. The main objective in this study is not to compare the contributions of alternative oil production and revenue scenarios to the economy, but instead to evaluate economic and socioeconomic outcomes under alternative spending options. All oil simulations therefore assume the same oil production path and government revenue stream, but they differ in terms of how government saves or spends the revenue. A total of six oil scenarios are modeled. We elaborate below, and Table 1 summarizes.

We start off with a set of basic investment scenarios where we assume all oil revenue is invested domestically, or, alternatively, part of oil revenue is invested and the balance is transferred to a foreign oil fund. Also included in this set of scenarios is one where part of the revenue is transferred to households in the form of a welfare grant. The first simulation, named FND00INV, is a typical Dutch Disease scenario. It assumes that all public revenue is immediately used to finance public infrastructure investment spending. This means none of the government oil revenue is saved abroad in a fund. In general, in this scenario, additional foreign exchange revenue from oil production and exportation increases national income, which is used by private and public agents for consumption (this is an endogenous effect) and investment (via increased private savings, or by design via the government closure selected). The latter increases the economy's total capital stock until peak oil production is reached, but the increased public capital does not sustain significantly higher output over the entire simulation period, as the capital stock in the oil sector is subsequently reduced to replicate declining output as oil reserves are gradually depleted. The simulation therefore allows the pure demand-side effects of the price boom to be isolated: Absorptive capacity constraints are binding and the demand effects lead to a real appreciation and the typical restructuring of production observed during an oil boom.

We start off with a set of basic investment scenarios where we assume all oil revenue is invested domestically, or, alternatively, part of oil revenue is invested and the balance is transferred to a foreign oil fund. Also included in this set of scenarios is one where part of the revenue is transferred to households in the form of a welfare grant. The first simulation, named FNDOOINV, is a typical Dutch Disease scenario. It assumes that all public revenue is immediately used to finance public infrastructure investment spending. This means none of the government oil revenue is saved abroad in a fund. In general, in this scenario, additional foreign exchange revenue from oil production and exportation increases national income, which is 
Table 1 Summary of modeled baseline and oil scenarios

\begin{tabular}{l|l|l|l|l}
\hline $\begin{array}{l}\text { Simulation } \\
\text { name }\end{array}$ & Long name & $\begin{array}{l}\text { Share of } \\
\text { revenue } \\
\text { invested }\end{array}$ & $\begin{array}{l}\text { Productivity } \\
\text { spillover } \\
\text { effects } \\
\text { modeled }\end{array}$ & $\begin{array}{l}\text { Share of } \\
\text { revenue } \\
\text { saved to oil } \\
\text { fund }\end{array}$ \\
\hline 0. BASELINE & $\begin{array}{l}\text { "Business as usual" baseline } \\
\text { scenario with no oil production } \\
\text { and refining capacity }\end{array}$ & N/A & N/A & N/A \\
\hline
\end{tabular}

Public investment scenarios with no productivity spillover

\begin{tabular}{l|l|l|l|l}
\hline 1. FND00INV & Fund 00 investment scenario & $100 \%$ & No & $0 \%$ \\
\hline 2. FND50INV & Fund 50 investment scenario & $50 \%$ & No & $50 \%$ \\
\hline 3. FND00I\&H & $\begin{array}{l}\text { Fund 00 investment and house- }^{\text {hold transfer scenario }}{ }^{\text {a }}\end{array}$ & $50 \%$ & No & $0 \%$ \\
\hline
\end{tabular}

Public investment scenarios with productivity spillover effects

\begin{tabular}{l|l|l|l|l}
\hline 4. FND50NTR & $\begin{array}{l}\text { Fund 50 investment scenario } \\
\text { with neutral productivity } \\
\text { spillover }\end{array}$ & $50 \%$ & Yes & $50 \%$ \\
\hline 5. FND50AGR & $\begin{array}{l}\text { Fund 50 investment scenario } \\
\text { with agricultural productivity } \\
\text { spillover }\end{array}$ & $50 \%$ & Yes & $50 \%$ \\
\hline 6. FND50NAG & $\begin{array}{l}\text { Fund 50 investment scenario } \\
\text { with nonagricultural productiv- } \\
\text { ity spillover }\end{array}$ & $50 \%$ & Yes & $50 \%$ \\
\hline
\end{tabular}

Source: Authors' estimations

Notes: (a) Uniform cash grant; $50 \%$ of oil revenue distributed to citizens

used by private and public agents for consumption (this is an endogenous effect) and investment (via increased private savings, or by design via the government closure selected). The latter increases the economy's total capital stock until peak oil production is reached, but the increased public capital does not sustain significantly higher output over the entire simulation period, as the capital stock in the oil sector is subsequently reduced to replicate declining output as oil reserves are gradually depleted. The simulation therefore allows the pure demand-side effects of the price boom to be isolated: Absorptive capacity constraints are binding and the demand effects lead to a real appreciation and the typical restructuring of production observed during an oil boom.

The second simulation, FND50INV, examines the case where only half of the oil revenue is invested immediately in public infrastructure while the remainder is deposited in a foreign oil fund. Government may choose this option in an attempt to mitigate or sterilize the Dutch Disease effects associated with a spend-all approach. Sterilization will reduce the growth effects relative to the experience of a massive spending boom, but at the same time the real exchange rate appreciation will be less pronounced since not all oil revenue from exports is brought back into the domestic economy. Although this may benefit export sectors in the short run, the net effect in the long run is not certain since investment flows and capital stock formation is lower in this scenario. 
A third simulation, FNDOOI\&H, investigates the option of using oil revenues to finance an unconditional uniform cash transfer scheme. This simulation assumes no deposit in a foreign oil fund; instead, half of oil revenue is spent on infrastructural investments (as in FND50INV) and the remainder is distributed equally among Uganda's citizens. The cash transfer is modeled as a nonuniform income tax cut across all household groups. The extent of the tax break varies across household groups in the model such that each citizen, irrespective of his or her age, receives the same per capita transfer in absolute terms (that is, initial average income tax rates and the size of household groups are taken into account in the calculation of the applicable tax cuts). In relative terms, therefore, poorer citizens receive a much larger welfare transfer than wealthy citizens. Since average tax rates are low in Uganda, several household groups end up with a negative tax rate, which effectively means their earnings from welfare transfers exceed income tax payments. If such a uniform grant scheme ever became a reality in Uganda it could be justified on the basis that each citizen in Uganda is entitled to an equal share of oil revenue. The design of the transfer mechanism implies that household incomes will rise across the board by the same absolute magnitude, causing poverty rates to decline, but income inequality will remain virtually unchanged. In contrast to the earlier scenarios, this simulation will lead to a significant increase in private disposable income, which is used by households to increase consumption and savings. The latter, in turn, finances private investment formation. Low savings rates, however, suggest that most of the additional income will be spent on household consumption.

Whereas the first set of oil simulations assume zero productivity spillover effects from public investments, the second set of simulations explore the importance of such productivity spillover. The aim here is to demonstrate not only the importance, in general, of ensuring that public investments are indeed productivity-enhancing, but also to show how investments that aim to raise productivity in specific sectors in the economy (for example, through direct targeting of agricultural or nonagricultural sectors) may ultimately have important growth and welfare or distributional implications. The scenarios all follow the same basic setup as FND50INV (that is, half of revenues are saved abroad and the other half is allocated to public infrastructure investments), but now assume that government infrastructure investment raises productivity relative to the growth already assumed in $B A S E L I N E$. In FND50NTR the productivity-enhancing effect is uniform or neutral across sectors, whereas in FND50AGR and FND50NAG total factor productivity growth is biased in favor of agricultural/food-processing and nonagricultural sectors, respectively.

The extent of the total factor productivity spillover effects in each sector is linked directly to the level of spending on each of several budget items. Equation (3) defines this relationship. Thus, as explained before, any increase (or decrease) in the real government investment index $I_{t}^{g} / I^{g}{ }_{0}$ in relation to the sector production index $Q_{s, t} / Q_{s, 0}$ raises (or reduces) sectoral total factor productivity $A_{s, t}$, with the extent of the increase (reduction) determined by the spillover parameter $\rho_{s g}$. In the first set of investment simulations $\rho_{s g}$ was set to zero, whereas in the spillover simulations $\rho_{s g}=0.1$. Since the structure of government spending is likely to have a 
bearing on sectoral productivity spillover effects (Fan et al. 2009), FND50AGR and FND50NAG assume both an increase in total government investment spending (as in FND50INV) and also a change in the composition of that spending. Data on the current budget composition are obtained from Sennoga and Matovu (2010) and Twimukye et al. (2010). In FND50AGR we increase the allocation to agriculture by $20 \%$ (or $0.8 \%$ points) from 3.8 to $4.6 \%$ of total budgetary resources, while at the same the expenditure share to roads is reduced by $0.8 \%$ points. In FND50NAG we assume the opposite, that is, the expenditure share on agriculture is reduced by $0.8 \%$ and vice versa for roads. Next, growth-expenditure elasticities (from Benin et al. 2008) are applied to calculate the marginal effect of the absolute and compositional shift in public expenditure sectoral productivity. The growthexpenditure elasticity for agricultural spending is 1.4 , whereas it is 2.7 for roads. The result is that total factor productivities in agriculture and food-processing sectors increase by about $25 \%$ in FND50AGR, while they decrease by about $10 \%$ in other manufacturing and trade and transport sectors (these changes are relative to the growth rate in BASELINE). The effects are the exact opposite in FND50NAG. In the neutral spending scenario (FND50NTR) there is no compositional shift in spending, hence productivity across all sectors grows by the same margin.

\section{Model Results}

\subsection{Public Investment Scenarios with No Productivity Spillover Effects}

\subsubsection{Spending All Revenues on Infrastructure (FNDO0INV)}

The major effects and transmission channels of the oil boom in Uganda are described with reference to the results of scenario FNDOOINV, which serves as the benchmark for other oil scenarios. Public investment expenditures are linked directly to government oil revenue and will therefore increase until peak oil production is reached in 2017. Thereafter these expenditures gradually decline due to declining government oil revenues (which in turn is linked to the real exchange rate appreciation) and the gradual winding down of oil production activities.

Under FNDOOINV the Ugandan economy grows rapidly at $6.9 \%$ per year until 2017, mainly because of the large increase in real public-sector investment (see Table 2: Part A). Overall investment grows at 9.5\% per year over this period. Household income also rises in these scenarios, which leads to an increase in private consumption (by 5.1\% during 2007-2017) and savings. However, private savings as a share of GDP actually declines (not reported in Table 2), which suggests the oil boom crowds out private-sector investment, at least in relative terms. A further factor is the real exchange rate appreciation. Although in general such an appreciation would mean imported capital goods become less expensive, 


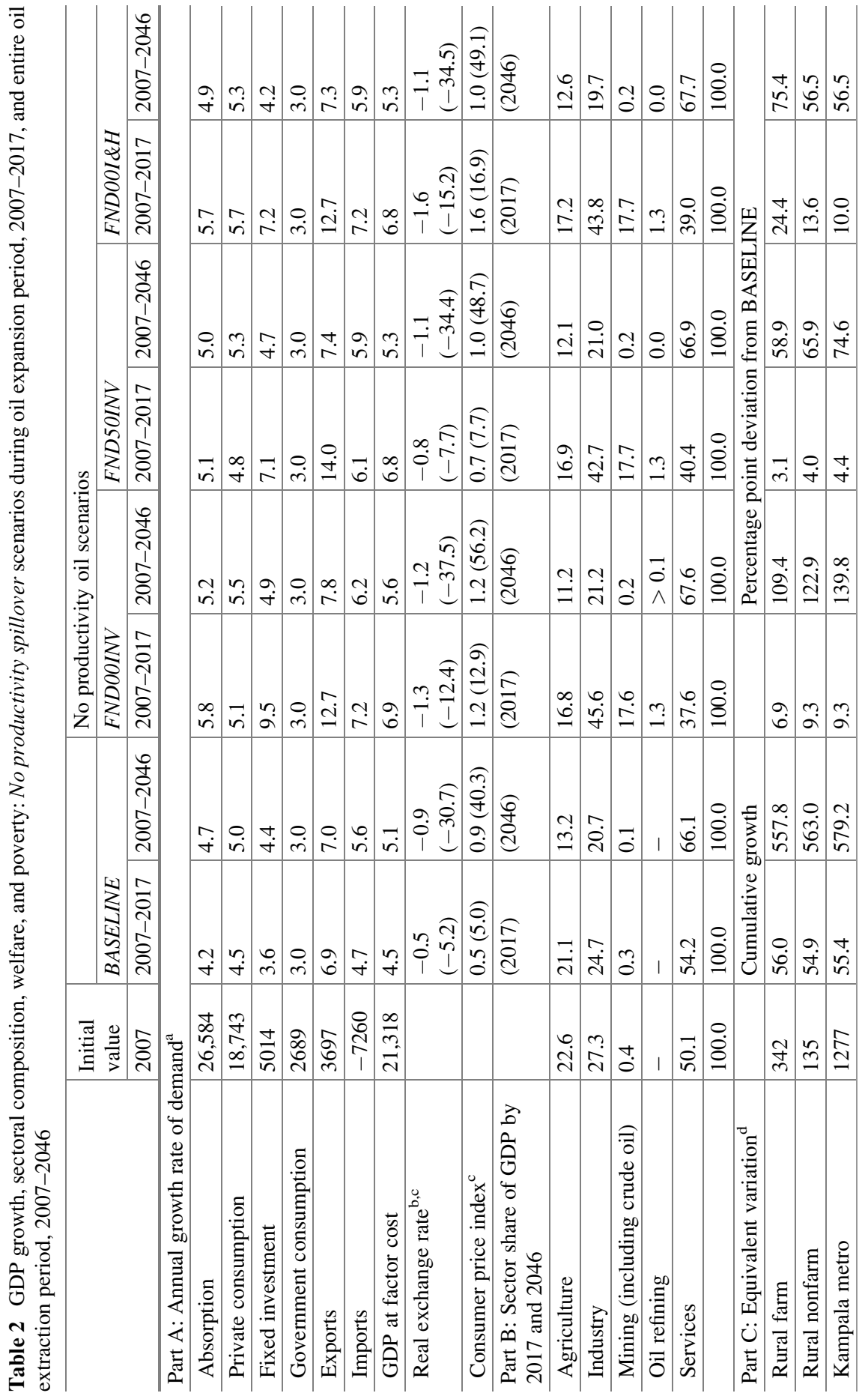




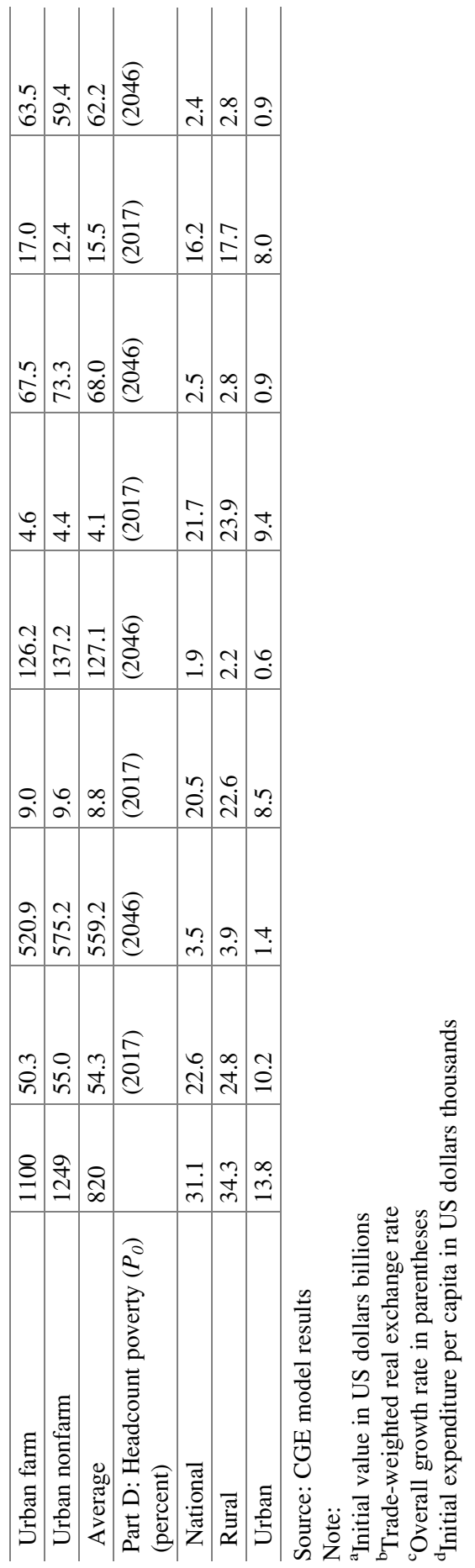


capital formation in Uganda is in fact intensive in nontradable goods (for example, nontradable construction goods make up $78 \%$ of investments). This means that foreign capital inflows, which are assumed to grow at 3\% annually in all scenarios, finance less and less real investment over time. Diminishing oil reserves means the real exchange rate appreciation weakens over time, but this is not sufficient to reverse the trend of declining non-oil exports. In fact, the initial welfare gains associated with the surge in public-sector investment weaken over time as other components of GDP (for example, private investments, consumption, and exports) fail to grow more rapidly when public investments eventually decline.

A comparison of FNDOOINV with BASELINE reveals the typical characteristics of Dutch Disease. The consumer price index increases at an average annual rate of $1.2 \%$ during 2007-2046, while the (trade-weighted) real exchange rate appreciates by $1.3 \%$ between 2007 and 2017 or by $1.2 \%$ per year over the entire 2007-2046 period. Relative to BASELINE, the spending of windfall revenues leads to a 0.2 and $1.5 \%$ point contraction in agriculture and services, respectively, in the medium term. As a result, these two sectors' shares of GDP also decline dramatically by 4.6 and $16.4 \%$ points relative to the base (2007-2017; see Table 2: Part B). The services sector regains growth momentum in the long run, but agricultural growth only improves marginally relative to the base. Thus, while real GDP at factor cost increases, the agricultural sector actually suffers a decline in GDP, both absolutely (compared to BASELINE) during the oil expansion period and relative to other sectors over the total oil extraction period (Table 2: Part B). The services sector also realizes absolute income losses in the medium term, but a reversal of fortunes sees this sector become the engine of long-term growth. ${ }^{1}$

Table 3 presents more disaggregated sectoral production results (GDP at factor cost), focusing on changes during the oil expansion period (2007-2017). The first column shows the average annual change in BASELINE, and the remaining columns show the percentage point changes in production in the various oil scenarios relative to BASELINE. The results for FNDOOINV corroborate the picture of Dutch Disease. Crude and refined oil production expand tremendously, while less tradable subsectors in agriculture, industry, and services also expand production. Within agriculture, export-oriented crops and other agriculture (which includes fisheries, a fairly significant exporter) suffer the greatest declines relative to the base, mainly due to the adverse real exchange rate effects on the trade competitiveness of these subsectors. The same is true for sectors such as fish processing and hotels and catering, both of which are highly export-oriented.

Government spending patterns also determine different sectors' relative performance under FNDOOINV. Increased government expenditure on investment goods leads to a sharp increase in demand for construction services (nontraded) and machinery (mostly imported) in particular. This in turn leads to an indirect increase in demand for intermediate input goods typically supplied by manufacturing and

\footnotetext{
${ }^{1}$ Of course, the observed structural shift is also a feature of the BASELINE scenario, and is, to a large extent, a natural outcome for any developing country's growth path.
} 


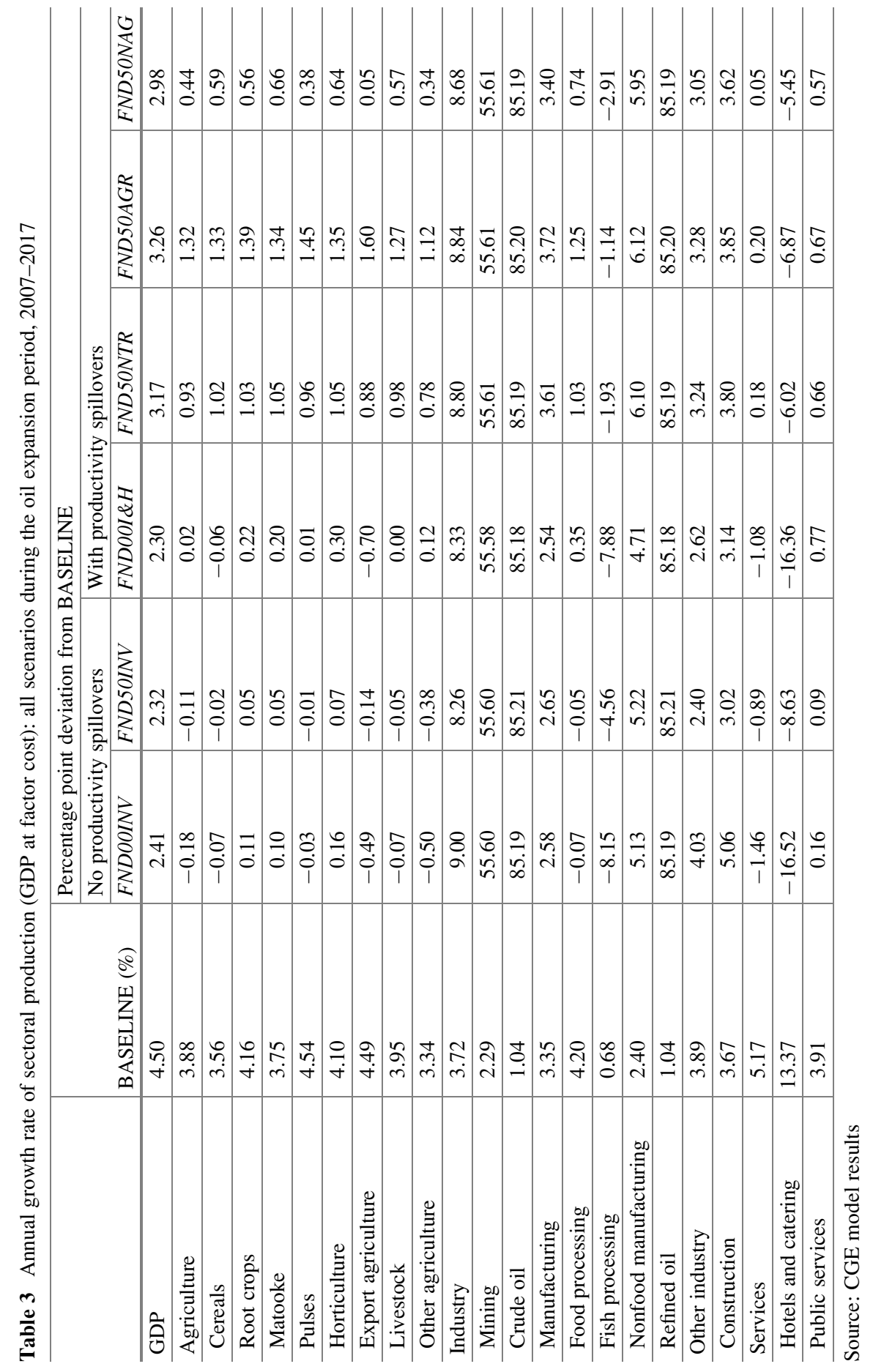


services sectors. Despite increased economic activity in nonagricultural sectors (that is, industry in particular), the knock-on effects for nontradable agricultural subsectors is almost negligible.

The contraction of production under FNDOOINV is most pronounced in cotton; tobacco; flowers; coffee; and tea, cocoa, and vanilla, where most or all of total production is exported. These sectors do not benefit from higher prices as a result of increasing domestic demand but are negatively affected by higher factor costs and higher prices for intermediate inputs. The latter also holds true for importcompeting cereals (maize, rice, other cereals), pulses (oilseeds and beans), and livestock. Though these sectors are more oriented toward the domestic market and therefore benefit from generally higher domestic income, demand elasticities are fairly low and the demand effect is not strong enough to compensate for the negative supply effect. Moreover, producers of maize, rice, other cereals, and oilseeds face competition from foreign suppliers. Given the high substitution possibilities for agricultural goods in domestic demand, the expansion of domestic demand is insufficient to counter the substitution effect. The assumption of zero productivity spillover effects in this scenario also explains the weak performance of nontradable agricultural subsectors. As later results show, these adverse effects can be offset by using oil revenues to raise agricultural productivity. The contraction of fisheries results from strong forward linkages to fish processing, a highly exportoriented food-processing sector, which suffers from Dutch Disease effects.

Only a select few agricultural subsectors (root crops, matooke, and horticultural crops) and forestry realize an increase in production in FND00INV relative to BASELINE. These benefit from increasing domestic private demand as a result of higher private income. In the former three sectors, private demand expansion is sufficiently strong to induce price increases, which overcompensate cost increases. Forestry is also a pure nontradable, and though not directly consumed, benefits from its forward linkages to the furniture industry, which is an investment-goods industry and therefore directly affected by increased public investment demand.

We next turn to welfare and household poverty results. The equivalent variation (EV) measures welfare improvements after controlling for price changes (see Table 2: Part C). Under BASELINE there is a marked improvement in the EV measure, with all household groups experiencing an increase in $\mathrm{EV}$ of between 4.8 and 5\% on average per year over the 2007-2046 period (or 520-575\% on aggregate). Gains are also fairly equally distributed, with rural farm households gaining slightly more thanks to a relatively rapid agricultural productivity growth rate assumed in BASELINE. Sustained GDP growth of just over 5\% per year will virtually eliminate poverty by 2046 (Table 4: Part D); the national poverty headcount (P0) drops to about $3.5 \%$ from $31.1 \%$ in the base. ${ }^{2}$

The introduction of oil (FNDOOINV) sees more rapid improvements in EV for higher income urban and nonfarm households than for rural farming households.

\footnotetext{
${ }^{2}$ Similar rates of decline are observed for the depth of poverty measure but are not reported in Table 2.
} 


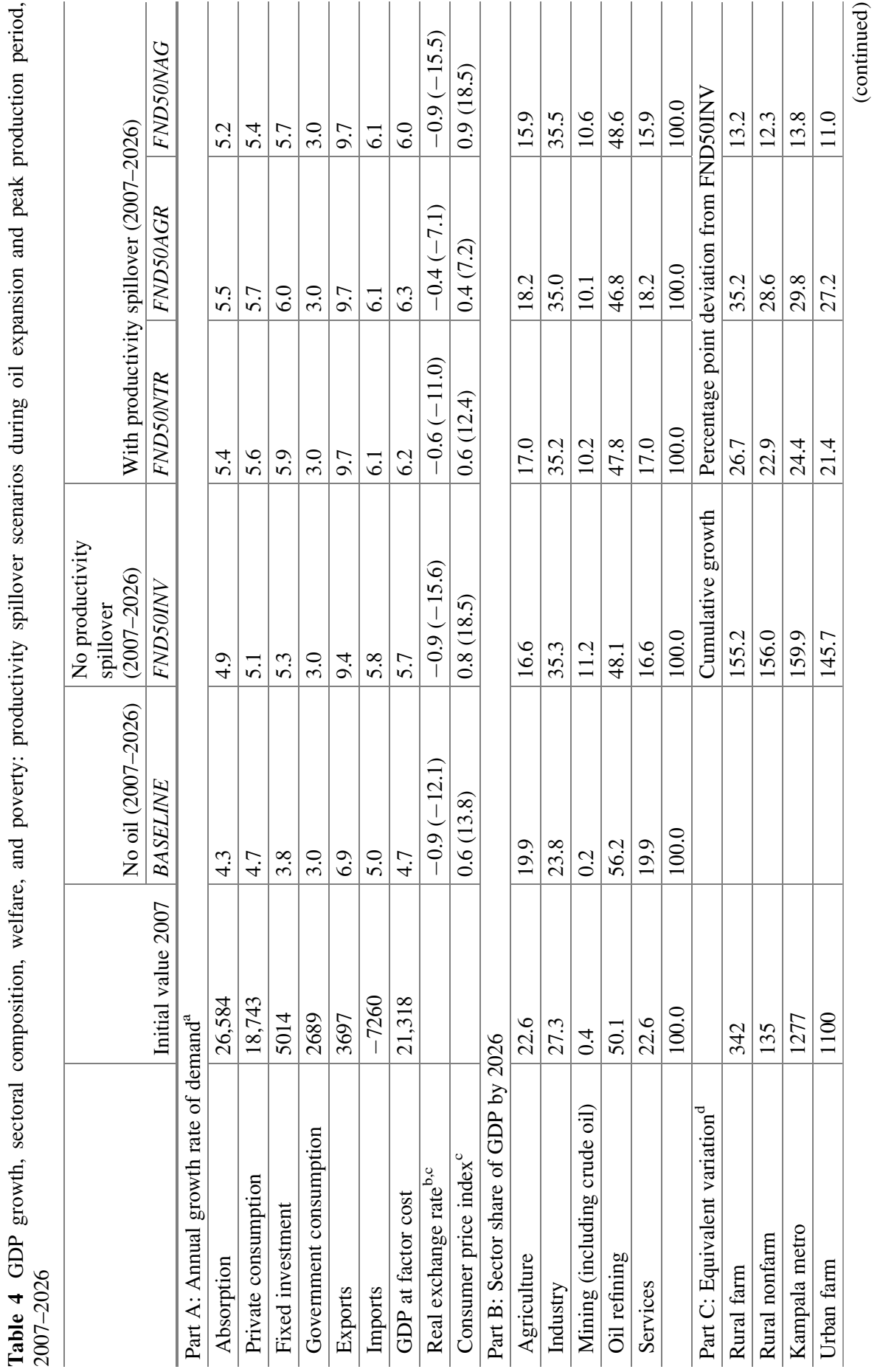




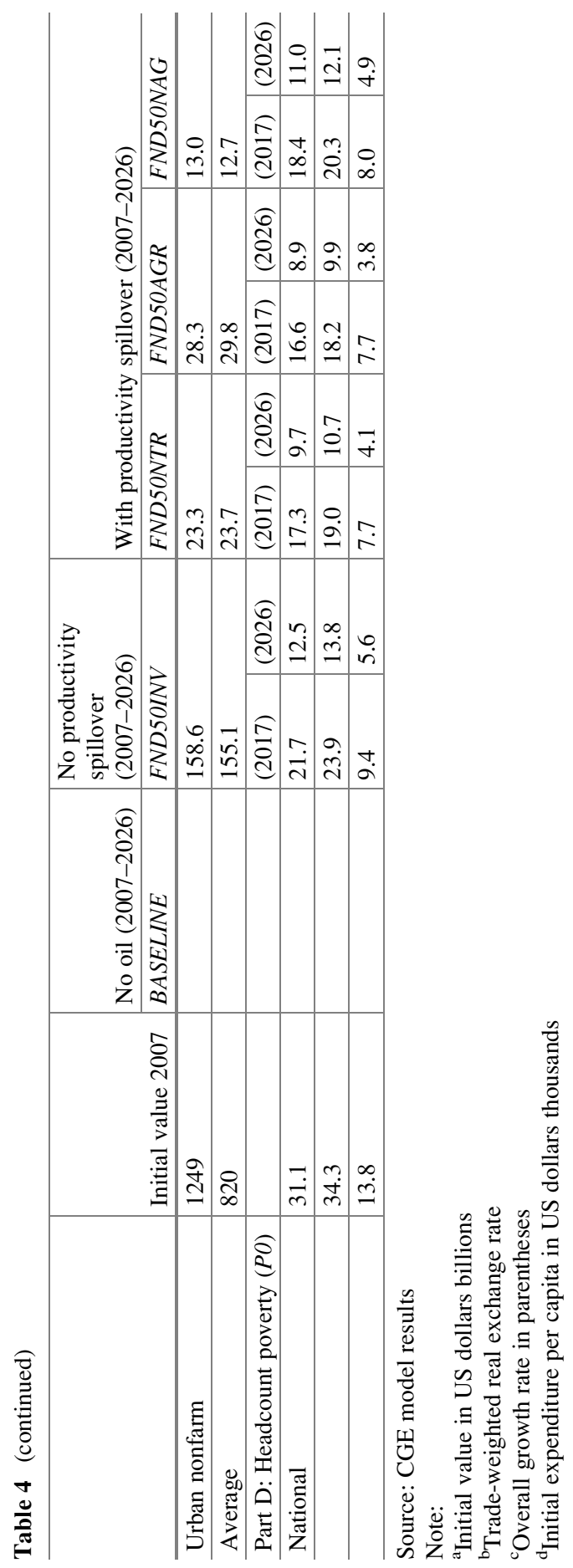


This relates to oil production, construction, and nonfood manufacturing being more capital and skilled-labor intensive, which means increases in factor returns in these sectors tend to benefit higher income and urban households. Self-employed family labor in the agricultural sector is furthermore assumed to remain in the agricultural sector, which means farm households do not benefit much from increasing labor demand and higher wages in nonagricultural sectors, yet they face the same consumer price increases as all other households in the economy. The uneven distributional outcomes under FNDOOINV are also reflected in poverty outcomes. Although the oil boom leads to a larger overall reduction in poverty relative to BASELINE, urban poverty declines faster than rural poverty. For example, by 2017 rural poverty is $22.6 \%$ in FNDOOINV, an $8.8 \%$ drop from the BASELINE rate of $24.8 \%$. In contrast, the urban poverty rate is $16.1 \%$ lower by in FNDOOINV relative to BASELINE by 2017.

Summing up, channeling windfall oil revenue into the Ugandan economy poses a number of challenges. The first one is the likely appreciation of the real exchange rate-the increase in the price of nontradable goods and services, in particular construction - as demand for them increases with windfall revenue in the face of a limited supply response, and its corollary in terms of lost export competitiveness in agriculture and food processing. The second one is the likely drop in overall productivity, as more factors get concentrated in nontradable sectors where potential productivity gains are much scarcer. The third one is the existence of reallocation (investments, migrations) and transition costs (lost markets and know-how), which can make temporary specialization costly overall if the society has to return to its previous specialization patterns. This risk exists with oil in Uganda, given its exhaustible nature, the shape of the likely extraction path, and the possibility that it conducts to an untenable pattern of specialization if government oil revenues are immediately invested and public investments do not confer any spillovers on private-sector productivity.

\subsubsection{Transferring Oil Revenues to a Foreign Oil Fund (FND50INV)}

In the face of severe Dutch Disease effects, Uganda could consider fixing the share of oil revenue to be transferred to the budget and investing the remainder abroad. The impact of such a sterilization strategy is analyzed in scenario FND50INV, which assumes that only half of current oil revenue is used to finance public infrastructure investment while the other half is saved in an oil fund abroad. This fund is assumed to be some variant of a permanent income fund (PIF) from which no withdrawals are made during the simulation period. Since none of the invested oil funds make their way back into the economy over the simulation period, we do not explicitly account for interest earned when calculating the cumulative fund value. However, with the nominal exchange rate as numéraire in the model all deposits into the fund are real values; hence, the fund also does not depreciate in value. As a share of GDP the fund reaches more than 50\% of GDP by about 2030. After this the fund as a share of GDP declines as no additional oil revenues are deposited into the fund but GDP continues to grow exponentially. 
Sterilizing part of the oil revenue and reducing government investment spending leads to less overall investment, less capital accumulation, and lower private consumption and absorption in the medium term (2007-2017). This causes GDP growth to decline marginally in FND50INV compared to FND00INV, although growth still exceeds that observed in BASELINE (Table 2: Part A). Capital outflows (that is, deposits into the oil fund) cause a much smaller real exchange rate appreciation in FND50INV, which means the restructuring of supply from tradeoriented sectors with relatively higher total factor productivity growth (for example, agriculture and certain services sectors) toward domestic-market-oriented industrial sectors with lower total factor productivities is less pronounced. This relative productivity gain coupled with the improved export performance almost entirely makes up for the GDP loss associated with the $50 \%$ reduction in oil funds invested and the lower level of capital accumulation, at least in the medium term. In the long run, however, total factor productivity effects in FND50INV are insufficient to compensate for the lower levels of capital accumulation, with overall GDP growth now deviating more from that in the previous scenario. At the $3 \%$ real government consumption growth rate imposed in all these scenarios the adjustment cost falls on private households, with private consumption growing by only 0.2 and 0.3\% points more than in BASELINE during 2007-2017 and 2007-2046, respectively, compared to $0.5 \%$ points in $F N D 00 I N V$ (both periods).

Tradable and nontradable agricultural subsectors are affected differently by the sterilization of oil revenues. Relative to FNDOOINV, the lower real appreciation improves the competitiveness of export-oriented and import-competing agricultural subsectors. In both types of subsectors, lower costs for nontradable intermediate inputs improve these sectors' domestic terms of trade. In addition, lower price increases on domestic markets, due to less expansion of private domestic consumption, imply that the spread between domestic prices and import and export prices is less pronounced. Thus, on the supply-side, the extent of export reduction is lower in all export-oriented subsectors, whereas on the demand-side, part of the substitution of domestic supply by imports is avoided. Both types of adjustments-export penetration and import substitution-benefit agricultural producers of export crops and agricultural import substitutes. As a result, the contraction of production in these sectors is less pronounced in FND50INV compared to FND00INV (see Table 3). In contrast, agricultural nontradable goods, such as root crops, matooke, and horticulture, are negatively affected by lower private consumer demand, the latter being the result of lower overall income in the Ugandan economy compared to the full spending scenario.

The welfare (EV) results for FND50INV in Table 2 (Part C) indicate that, while all households suffer from welfare losses as a result of sterilization, nonfarm households in Kampala and other urban areas will lose out most from the resultant lower levels of public investment. There are two reasons for this result: First, the positive income effect of a higher capital rental rate (for now scarcer capital) is more than offset by lower capital availability; second, wage increases for skilled labor, which is another primary source of income for urban households, are also lower compared to FNDOOINV. The rate of poverty reduction is also lower in all 
household groups if part of the oil revenue is sterilized (Table 2: Part D). Thus, while sterilization counters Dutch Disease and possibly allows future generations to benefit from increased spending of oil revenues that are saved now, it also means that fewer benefits are transferred to citizens in the medium term.

\subsubsection{Transferring Rents to Citizens (FND00I\&H)}

We next consider a scenario where poverty is targeted directly by redistributing part of oil revenues directly to citizens rather than saving funds in an external oil fund. As a variation of FNDOOINV, FND00I\&H evaluates the option of investing half of oil revenue in infrastructure while the other half is distributed to citizens as a direct welfare transfer. Each citizen receives the exact same per capita transfer. Households use this windfall to finance additional consumption spending or to save, depending on the average savings propensities specified for different household groups in the CGE model. The grant being uniformly distributed implies that poorer households receive a larger relative transfer. Figure 1 shows the impact of the welfare grant on average per capita income in 2017 when peak production is reached and the transfer value is at a maximum.

The figure shows that prior to receiving the welfare grant, rural farm households have a per capita income of USh900,000 per year in 2017 (approximately \$375, or just more than $\$ 1$ per person per day). The welfare transfer, modeled as a tax rebate, adds a further USh129,000 to their income (\$50-60 per person per year); thus, as a share of income the transfer is worth $14.4 \%$ to these households. At the other end of the income spectrum are citizens of Kampala with a per capita income of USh5.4 million. To these people the transfer of USh129,000 is worth only $2.4 \%$ of their

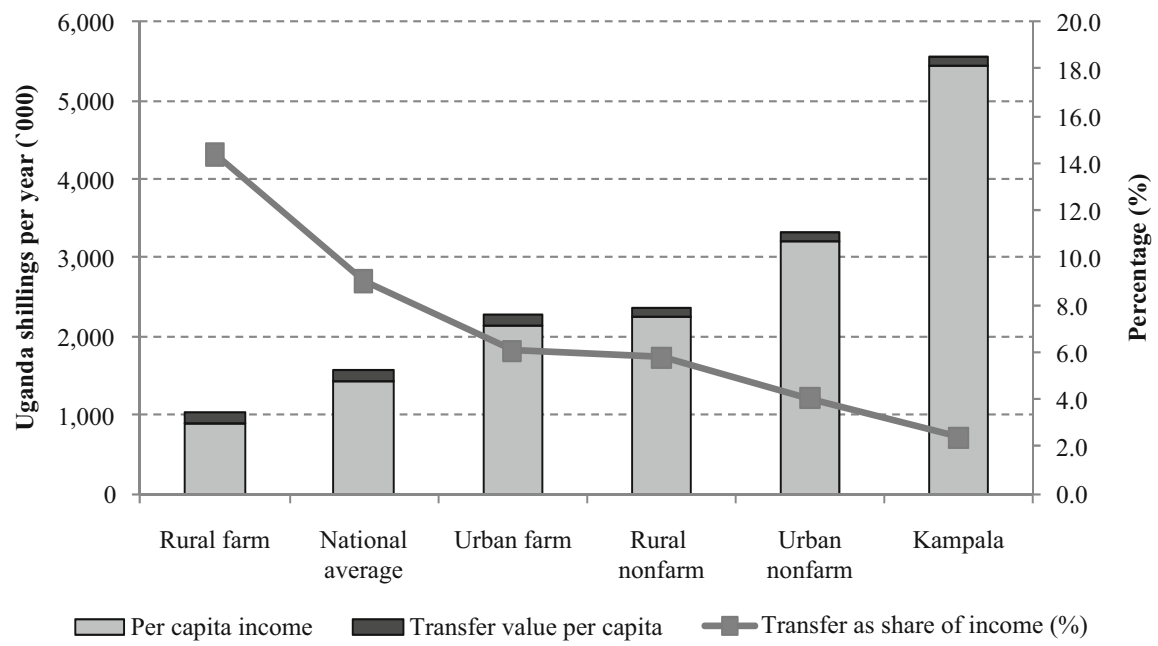

Fig. 1 Average per capita income and per capita transfer values (FND00I\&H), 2017. Source: CGE model results 
income. About three-quarters of Ugandans live in rural farm households; hence, the national average per capita income is only slightly above that of rural farm households (USh1.4 million), whereas the transfer is worth $9 \%$ of income.

Despite price increases, the expansion of private household consumption benefits the agricultural sector as a whole, with overall agricultural GDP growth in FNDOOI\&H marginally higher than in BASELINE (agricultural growth declined relative to BASELINE in both FNDOOINV and FND50INV). However, the real exchange rate appreciation accompanying the expansion of private consumption induces structural changes both across and within agricultural subsectors in terms of production for the domestic and world markets. In particular, the expansion of private consumption benefits producers of nontradable agricultural goods such as root crops, matooke, horticulture, livestock, and forestry. Export agriculture is now even more negatively affected compared to FND50INV due to production cost increases and a stronger real exchange rate. Similarly, import-competing agricultural subsectors, such as cereals and oilseeds, also contract as a result of production cost increases and stronger competition from abroad. In all these subsectors, the demand effect from increased private consumption is not sufficiently strong to compensate for the negative import substitution effect that results from the real exchange rate appreciation. With relatively inelastic demand and strong substitution possibilities between domestic and imported agricultural foodcrops, the substitution effect overcompensates the demand effect.

Compared to the first two experiments, the redistribution of rents creates more employment opportunities in agriculture and leads to significantly higher land rentals and prices for livestock. Thus, a larger share of factor income accrues to rural households, who in turn spend a larger share of their incomes on goods produced domestically and in rural areas. This is corroborated by changes in the EV presented in Table 2 (Part C). These results indicate that welfare improves more rapidly for lower income rural and urban farm households than for higher income nonfarm households. Of course, this result also stems directly from the welfare transfer itself, which in relative terms causes incomes of poorer households to increase more than that of wealthier households (Fig. 1). Moreover, the redistribution of oil rents leads to more consumption by all households, and since production of consumption goods (agricultural and food products in particular) is more land and unskilled-labor intensive, the resulting increases in these factor returns benefit lower income and rural households more.

The uneven distributional impacts are also reflected in poverty outcomes (Table 2: Part D). Between 2007 and 2017 the redistribution of oil rents leads to a significant decline in poverty at the national level, and also relative to BASELINE and the first two oil production scenarios. Moreover, rural poverty declines more rapidly than urban poverty. In fact, redistribution is twice as effective at reducing poverty among rural households compared to other rent spending options considered. By 2046, however, poverty outcomes under FND00INV are superior to those under FNDOOI\&H. This suggests that investments have longer lasting benefits in terms of production capacity and employment in the future. This benefits the poor more in the longer term than welfare handouts in the medium term. Of course, there 
are several caveats, one of which is the fact that we assume households' expenditure patterns remain unchanged after receiving welfare transfers. In reality, households may choose to invest extra income earned in (say) education, which will raise their productivity and future employability. We also do not consider productivity spillover effects of the investments themselves, which is the focus of the next set of experiments.

\subsection{Public Investment Scenarios with Productivity Spillover Effects}

In this set of simulations we once again model an increase in public investments, now assuming that these investments have productivity spillover effects in the private sector. All scenarios use FND50INV as the basis, with productivity spillover effects determined by both the level of investment spending and its structure. The first simulation, FND50NTR, assumes a neutral allocation of public investment spending. This assumes increased spending has a uniform productivity-enhancing effect across all sectors of the economy, that is, total factor productivity in all sectors grow by the same margin, in percentage terms, over and above the growth already defined in BASELINE. In the second simulation (FND50AGR) we model the effect of agricultural-biased public investment spending. This means spending is targeted toward improving agricultural productivity relative to nonagricultural productivity through investing relatively more in (for example) rural and agricultural infrastructure. In this scenario the productivity effects of government infrastructure are restricted to agricultural value-added chains (agricultural sectors and food-processing sectors) and core agricultural inputs, such as communications, banking, and real estate services (this serves to alleviate possible supply constraints in input markets). Finally, FND50NAG investigates a restructuring of public investment expenditures toward urban infrastructure at the expense of agriculturerelated infrastructure.

In the discussion of results it is important to note that the three scenarios are not necessarily directly comparable as far as overall performance of the economy is concerned. Although a formulaic approach is adopted for determining the productivity shock associated with a certain level and structure of public investment, we do not consider the efficiency of such public spending across different sectors. In reality, cross-sectoral differences in initial productivity rates and productivity growth potential imply that the cost of achieving (say) a $1 \%$ increase in productivity may differ from one subsector to the next. What we can (and indeed do) compare are structural differences between the different scenarios. We also compare economic performance in the three productivity spillover scenarios to the no productivity spillover scenario (FND50INV).

Table 4 presents the simulation results. Here we only focus on the 2007-2026 period, which includes the run-up to peak oil production as well as the decade 
during which peak production levels are sustained. All three productivity spillover scenarios assume the same increase in public infrastructural investments as in FND50INV. Initially, as public infrastructural investments rise in line with oil revenue increases, the productivity spillover scenarios are exactly the same as FND50INV. It is only by 2020 that we assume the productivity spillovers take effect (that is, we allow for a 3-year lag from the time public investments peak in 2017 until a higher level of productivity growth is reached). At this point we observe a fairly substantial additional GDP growth impact in all three scenarios relative to FND50INV, such that growth over the 2007-2026 period exceeds growth in FND50INV by between 0.3 and $0.6 \%$ points across the three productivity spillover scenarios. Even though the same level of oil-funded public investment is assumed in all these scenarios, the increased economic activity means that there is a marked rise in total annual investment as private savings increase.

Real exchange rate and price impacts differ substantially across the three scenarios. Although the real exchange rate appreciates in all these scenarios, it depreciates relative to BASELINE, and in FND50NTR and FND50AGR the real exchange also depreciates relative to $F N D 50 I N V$. In contrast, the real exchange rate in FND50NAG is virtually unchanged from what was observed in BASELINE and FND50INV. The combined effect of increased productivity and more favorable terms of trade in at least two of the scenarios mean that export volumes increase in all three productivity spillover scenarios. This is illustrated by the improved performance of sectors such as export-oriented agriculture, livestock, other agriculture, and food processing, all of which grow relative to the decline in GDP observed in FND50INV (see Table 3). Other major exporters such as fish processing and hotels and catering show a relative improvement compared to FND50INV.

We have previously established that public investment spending in an oil production context and the assumption of no productivity spillovers tends to benefit urban nonfarm households more than rural farm households, since the latter group is largely bypassed as a result of missing backward linkages from rapidly growing industrial and services sectors. The productivity spillover scenarios now suggest a rapid improvement in the outcomes for rural farm households. All households still enjoy increases in welfare (EV) over time if public investment spending does not discriminate between sectors (FND50NTR), but, interestingly, the absolute and proportionate gains are now highest for rural farm households (Table 4: Part C). These altered distributional impacts are also reflected in the poverty results (Table 4: Part D), which show that rural poverty declines slightly faster than urban poverty. This relates to the Ugandan economy's ability to produce more tradable and nontradable goods as a result of productivity increases, whereas the reversal of the real exchange rate appreciation shifts the domestic terms of trade in favor of export-oriented and import-competing producers of tradable goods and against producers of nontradable goods. All agricultural sectors now expand their production, whereas export-oriented agricultural sectors increase their export supply. Thus, although many agricultural sectors shrank when public investments were unproductive (for example, in FND5OINV), the sector is able to expand as a result of productivity spillovers, even when not targeted directly as is the case in FND50NTR. 
In the case where nonagricultural sectors are targeted (FND50NAG), additional public investment spending on urban road infrastructure increases total factor productivity growth in the tradable nonfood-manufacturing sectors (that is, textiles, wood and paper, other manufacturing, machinery, and furniture) and in the trade, hotel and catering, and transport services sectors. At the same time we assume lower levels of spending on rural infrastructure, which reduces total factor productivity growth in all agricultural and food-processing sectors as well as in the lesstradable communications, banking, real estate, and community services sectors. As expected, when productivity growth is lower in sectors that predominantly supply goods for the domestic market (these are also goods that cannot easily be substituted by imports), the spending of oil revenues causes a larger (relative) appreciation of the real exchange rate than in the case of neutral productivity spillovers. Hence, although the manufacturing export performance is slightly stronger in machinery and equipment, hotels and catering, and transport, the agricultural sector is hit relatively hard when productivity gains are biased against it. At $4.1 \%$ per year, average agricultural growth in FND50NAG is half a percentage point lower than in FND50NTR, and the agricultural sector's share in GDP declines by more than a percentage point by 2026 vis-à-vis a neutral allocation of investment spending.

When public investment spending is biased in favor of agriculture and food processing (FND50AGR), outcomes are markedly different. Increased supply of agricultural goods and food items is sufficiently strong to more than offset the demand effects of the oil boom, such that the initial real exchange rate appreciation observed in FND50INV is reversed within a relatively short time. The effects on exports are a mirror image of those in FND50NAG; agriculture exports recover more strongly than in the former experiment, but lower productivity growth in nonfood manufacturing results in a more sluggish recovery in manufacturing exports.

The most striking difference between the two public investment options, though, is the effect on real household disposable incomes, welfare and poverty (Table 4: Parts C and D). Compared to FND50NTR, a manufacturing bias (FND50NAG) sharply moderates real income and welfare growth in the economy. The total rise in EV relative to FND50INV is only $12.7 \%$ points in FND50NAG compared to $23.7 \%$ points in FND50NTR. Moreover, the income gain is spread somewhat unevenly across household groups, with rural farm households now faring worse than Kampala households. This contrasts sharply with the outcome under FND50AGR, which generates markedly higher aggregate real income gains in the medium term $(29.8 \%$ points), and one that benefits poorer rural households more. Poverty outcomes for rural and urban households improve in the agricultural-biased scenario relative to the neutral scenario, whereas in the manufacturing-biased scenario poverty rates are higher compared to the neutral growth scenario. In all productivity scenarios, however, poverty rates decline more rapidly than in FND50INV.

Given the significant impact on agricultural growth and on the welfare of rural households of the agricultural productivity spillovers from the increased public investments arising from Uganda's oil revenue, it is critical that the Government of 
Uganda put in place mechanisms by which these productivity spillovers can be maximized. What is needed, in particular, is a well-coordinated set of interventions aimed at improving competitiveness in the agricultural sector, which would serve as a platform sustainable growth in the economy. However, at $3.8 \%$ of the budget, current spending on agriculture in Uganda is well below the $10 \%$ target committed to under the Comprehensive African Agricultural Development Program (CAADP). Research by Fan et al. (2009) suggests that agricultural research and development, infrastructure (such as rural roads), and investments in education and skills have the highest payoffs in terms of agricultural productivity gains and increased competitiveness of the sector.

\section{Conclusion}

Even at conservative prices of \$70-80 per barrel, future oil revenue in Uganda will be considerable, potentially doubling government revenue within 6-10 years and constituting an estimated 10-15\% of GDP at peak production. The economic impact of oil production on the country's agricultural performance and the livelihood of rural households could be profound, particularly during the first phase of the projected extraction when massive additional inflows of foreign exchange need to be managed by the Ugandan government. The so-called Dutch Disease effects may affect the international competitiveness of export sectors, such as agriculture in particular, and it is likely to make the country's growth strategy-with its emphasis on value-added, export diversification, and manufacturing-harder to achieve. This would threaten to increase, rather than decrease, the urban-rural income gap.

Agriculture and related processing currently contribute about $27 \%$ to GDP. Food and agriculture-related processing make up about $50 \%$ of household consumption expenditure. Poverty is higher in rural than in urban households and within rural households it is highest among nonfarm households. Even with no oil revenue, agriculture's share of GDP is projected to decrease by $6.8 \%$ points from $22.6 \%$ in 2007 to $15.8 \%$ over the next 40 years, as increasing factor productivities in tradable sectors and increasing per capita income and consumption will be leading toward a restructuring of production in favor of services.

It is important to differentiate between medium- and long-term impacts of oil revenue spending, since structural impacts differ and asymmetric adjustment flexibilities (ratchet effects) in factor markets (investments, migrations) and foreign trade (lost markets and know-how) can make temporary specialization costly if the Ugandan society has to return to its previous specialization patterns because of the exhaustible nature of oil reserves.

The impacts of oil extraction will be felt by Uganda mostly indirectly through higher government expenditures on consumption (largely administration) and 
investment; direct effects through higher domestic factor income in oil extraction and refining and through backward linkages will be minimal given production technologies and the economic enclave character of the oil industry. Results of this chapter suggest that the extraction and refining of oil will increase overall GDP growth, increase national and rural real household incomes, and benefit the poor in Uganda. In the medium term, that is, from the starting of oil extraction (2011 in this analysis) until reaching peak production (2017), overall average annual GDP growth will be between 2.3 and $3.3 \%$ points higher than in a comparable baseline projection without oil. In the long term over the total extraction path of 40 years, the average growth rate will be between 0.2 and $0.5 \%$ points higher. The differences depend on how oil revenues are spent, on whether public infrastructure confers any spillovers on private-sector productivity, and in which sectors these spillovers occur.

Several conclusions emerge from the simulations presented in this paper. First, with the projected oil extraction path and recently high oil prices, a real appreciation of the Uganda shilling is almost inevitable. Although policies designed to limit absorption through tight fiscal and monetary policies would reduce the pressure on the exchange rate over the short to medium term, they are unlikely to be sufficient to eliminate it. A rapid buildup of foreign exchange reserves and the accumulation of government oil revenue in some kind of external resource fund could mitigate the pressure but at the expense of domestic investment, the fiscal position, and private household welfare and consumption, as well as poverty reduction. In any case, agriculture and the rural population will be discriminated against by the expected oil boom. As net producers of tradable goods and net consumers of nontradable goods they suffer twice, from increased production costs and higher prices for consumer goods. Only a few select agricultural subsectors that produce exclusively for the domestic market, such as root crops, matooke, and horticulture, realize income gains as a result of generally higher income and consumption. Transferring part of the oil rent to citizens-rather than to a foreign oil fund-would directly increase household welfare and accelerate poverty reduction efforts. Moreover, agriculture as a whole would regain growth momentum. However, the real appreciation accompanying the oil-rent-financed expansion of private consumption would induce strong structural changes both across and within agricultural subsectors, which might be difficult to reverse once oil revenues dry out. Thus, there is the real danger of losing long-run competitiveness vis-à-vis foreign suppliers both on world markets for agricultural export commodities as well as on domestic markets for food products.

Second, Uganda's oil discovery comes at an opportune moment as the country battles with the challenges of marked infrastructural backlogs. In this situation of initial scarcity of public infrastructure, oil-funded increases in public infrastructure may lead to potentially large medium-term welfare gains, despite the presence of Dutch Disease effects. This is particularly true when public infrastructure augments the productivity of private factors. Yet, the sectoral and distributional consequences of these investments are highly sensitive to the structure and quality of public 
investment spending, which has an influence on the location of productivity effects, as well as the characteristics of demand.

Third, a neutral allocation of investment spending, which leads to a balanced sectoral supply response, is broadly beneficial to the Ugandan economy in terms of boosting aggregate growth and investment, welfare, and exports while moderating appreciation of the real exchange rate and reducing poverty on a significant scale, with rural poverty declining even faster than urban poverty. This relates to the Ugandan economy's ability to produce more goods - both tradable and nontradable - as a result of productivity increases, whereas a reversal of the real exchange rate appreciation shifts the domestic terms of trade in favor of exportoriented and import-competing agriculture. Thus, even though many agricultural subsectors would be indirectly discriminated against if there were no productivityenhancing public infrastructure, these sectors are able to expand as a result of productive public investment, even when not targeted directly. In contrast, agriculture is hit relatively hard when a reallocation of public investment spending leads to a nonagricultural bias in the supply response.

Fourth, outcomes are markedly different when public investment spending is biased in favor of agriculture and food processing. In this case results suggest that (1) the supply response of agriculture would be sufficiently strong to more than offset the demand effects of the oil boom; (2) agriculture exports would recover more strongly than with a neutral or a nonagricultural, industry-biased allocation of investment spending; (3) the supply response would generate higher aggregate real income gains; and (4) poorer rural households will benefit the most, but without sacrificing urban poverty reduction. With respect to the latter, a highly significant outcome is that poverty falls for both rural and urban households under an agriculture-biased public investment spending scenario (relative to a neutral spending strategy), whereas industry-biased spending would lead to comparably higher poverty in both regions.

Although direct comparisons of scenario results should be done with great caution, a simple ranking of public spending options according to growth, real income, and poverty reduction effects suggests an agriculture-biased investment strategy is the preferred option. Such a strategy would not only increase agricultural growth and rural incomes most, but would also have significant and positive spillover effects into the rest of the economy, thereby benefiting all segments of society. The recommendation is less clear in the zero-spillover scenarios. In this case, there is a trade-off between increasing investment (and therefore relatively higher overall growth) and increasing consumption (and therefore relatively higher agricultural growth). The latter (increased consumption), which is achieved by redistributing oil revenues to Uganda's citizens via a welfare transfer scheme, is associated with larger reductions in poverty, at the national level and particularly in poorer rural areas.

These conclusions must, of course, be qualified by a number of caveats. Among these is that absorption capacity and, consequently, the quality and efficiency of public investments for economic growth are critically important. Having oil revenues but then having to incur high economic and social costs in attempting to spend 
these revenues will lower the net benefits of oil. For balanced growth and poverty reduction to materialize a well-coordinated set of interventions aimed at improving competitiveness in the agricultural sector is needed. These may include investments in agricultural research and development, infrastructure (such as rural roads), and education and skills, with priority afforded to those investment areas that have the highest payoffs in terms of agricultural productivity gains and increased competitiveness of the sector. Any further analysis of the impact of oil in Uganda must pay closer attention to issues of spending efficiency and spending priorities.

\section{References}

Acemoglu, D., S. Johnson, and J. Robinson. 2003. Botswana - An African success story. In In search of prosperity: Analytical narratives on economic growth, ed. D. Rodrik. Princeton, NJ: Princeton University Press.

Adato, M., and J. Hoddinott. 2010. Conditional cash transfers in Latin America. Baltimore: Johns Hopkins University Press.

Ahmed, R., and M. Hossain. 1990. Developmental impact of rural infrastructure in Bangladesh. IFPRI Research Report 83. Washington, DC: International Food Policy Research Institute.

Antle, J. 1984. Human capital, infrastructure, and the productivity of Indian rice farmers. Journal of Development Economics 14: 163-181.

Benin, S., J. Thurlow, X. Diao, A. Kebba, and N. Ofwono. 2008. Agricultural growth and investment options for poverty reduction in Uganda. IFPRI Discussion Paper 790. Washington, DC: International Food Policy Research Institute.

Bevan, D., P. Collier, and J. Gunning. 1999. The political economy of poverty, equity, and growth: Nigeria and Indonesia, a World Bank comparative study. New York: Oxford University Press.

Binswanger, H.P., S.R. Khandker, and M.R. Rosenzweig. 1993. How infrastructure and financial institutions affect agricultural output and investment in India. Journal of Development Economics 41: 337-366.

Breisinger, C., X. Diao, R. Schweickert, and M. Wiebelt. 2009. Managing future oil revenues in Ghana. An assessment of alternative allocation options. IFPRI Discussion Paper 893. Washington, DC: International Food Policy Research Institute.

Calderón, C., and L. Servén. 2005. The effects of infrastructure development on growth and income distribution. World Bank Policy Research Working Paper 3643. Washington, DC: World Bank.

. 2008. Infrastructure and economic development in sub-Saharan Africa. World Bank Policy Research Working Paper W4712. Washington, DC: World Bank.

Canning, D., and E. Bennathan. 1999. The social rate of return on infrastructure investments. World Bank Policy Research Working Paper W2390. Washington, DC: World Bank.

Dervis, K., J. de Melo, and S. Robinson. 1982. General equilibrium models for development policy. Cambridge: Cambridge University Press.

Diao, X., P. Hazell, and J. Thurlow. 2010. The role of agriculture in African development. World Development 38 (10): 1375-1383.

Dorosh, P., and J. Thurlow. 2009. Agglomeration, migration, and regional growth. A CGE analysis for Uganda. IFPRI Discussion Paper 848. Washington, DC: International Food Policy Research Institute.

Duflo, E., and R. Pande. 2007. Dams. Quarterly Journal of Economics 122 (2): 601-646.

Easterly, W. 2001. The elusive quest for growth. economists' adventures and misadventures in the tropics. Cambridge, MA: MIT Press. 
Esfahani, H., and M.T. Ramirez. 2002. Institutions, infrastructure and economic growth. Journal of Development Economics 70: 443-477.

Fan, S., P. Hazell, and S. Thorat. 2000. Government spending, growth, and poverty in rural India. American Journal of Agricultural Economics 82 (4): 1038-1051.

Fan, S., T. Mogues, and S. Benin. 2009. Setting priorities for public spending for agricultural and rural development in Africa. IFPRI Policy Brief 12. Washington, DC: International Food Policy Research Institute.

Fan, S., and X. Zhang. 2008. Public expenditure, growth, and poverty reduction in rural Uganda. African Development Review 20 (3): 466-496.

Fan, S., L. Zhang, and X. Zhang. 2003. Growth, inequality, and poverty in rural China: The role of public investments. Research Report No. 125. Washington, DC: International Food Policy Research Institute.

Gelb, A. 1988. Oil windfalls: Blessing or curse? New York: Oxford University Press for the World Bank.

Gelb, A., and S. Grasmann. 2010. How should oil exporters spend their rents? Working Paper 221. Washington, DC: Center for Global Development.

Gelb, A., and S. Majerowicz. 2011. Oil for Uganda - Or Ugandans? Can cash transfers prevent the resource curse? Working Paper 261. Washington, DC: Center for Global Development.

Gibson, J., and S. Rozelle. 2003. Poverty and access to roads in Papua New Guinea. Economic Development and Cultural Change 52 (1): 159-185.

Hausmann, R., and R. Rigobon. 2002. An alternative interpretation of the "resource curse": Theory and policy implications. NBER Working Paper 9424. Cambridge, MA: National Bureau of Economic Research.

Hulten, C. 1996. Infrastructure capital and economic growth: How well you use it may be more important than how much you have. NBER Working Paper 5847. Cambridge, MA: National Bureau of Economic Research.

IMF (International Monetary Fund). 2003, September. World economic outlook. Washington, DC: International Monetary Fund.

Leite, C., and J. Weidmann. 1999. Does mother nature corrupt? IMF Working Paper 99/85. Washington, DC: International Monetary Fund.

Pauw, K., and L. Mncube. 2007. Expanding the social security net in South Africa: Opportunities, challenges and constraints. DPRU Working Paper No. 07/128. Cape Town: University of Cape Town, Development Policy Research Unit.

Ram, R. 1996. Productivity of public and private investment in developing countries: A broad international perspective. World Development 24: 1373-1378.

Reinikka, E., and J. Svensson. 2002. Coping with poor public capital. Journal of Development Economics 69 (1): 51-69.

Renkow, M., D.G. Hallstroma, and D. Karanjab. 2004. Rural infrastructure, transactions costs and market participation in Kenya. Journal of Development Economics 73 (1): 349-367.

Rodrik, D. 2003. What do we learn from country narratives? In In search of prosperity: Analytical narratives on economic growth, ed. D. Rodrik. Princeton, NJ: Princeton University Press.

Ross, M.L. 2001. Does oil hinder democracy? World Politics 53: 325-361.

Sachs, J. D., and A. M. Warner. 1995. Natural resource abundance and economic growth. NBER Working Paper 5398. Cambridge, MA: National Bureau of Economic Research.

Sachs, J.D., and A.M. Warner. 2001. The curse of natural resources. European Economic Review 45 (4-6): 827-838.

Sala-i-Martin, X., and A. Subramanian. 2003. Addressing the natural resource curse: An illustration from Nigeria. IMF Working Paper 03/139. Washington, DC: International Monetary Fund.

Sennoga, E. B., and J. M. Matovu. 2010. Public spending composition and public sector efficiency: Implications for growth and poverty reduction in Uganda. Research Series No. 66. Kampala: Economic Policy Research Centre. 
Stevens, P. 2003. Resource impact-Curse or blessing? A literature survey. Journal of Energy Literature 9 (1): 1-42.

Thurlow, J. 2004. A dynamic computable general equilibrium (CGE) model for South Africa: Extending the static IFPRI model. TIPS Working Paper 1-2004. Pretoria: Trade and Industrial Policy Strategies.

Thurlow, J., S. Morley, and A. N. Pratt. 2008. Lagging regions and development strategies. IFPRI Discussion Paper 898. Washington, DC: International Food Policy Research Institute.

Twimukye, E., J. M. Matovu, S. Levine, and P. Birungi. 2010. Sectoral and welfare effects of the global economic crisis on Uganda: A recursive dynamic CGE analysis. Research Series No. 73. Kampala: Economic Policy Research Centre.

Uganda, Ministry of Energy and Mineral Development. 2008. National oil and gas policy for Uganda. Kampala: Ministry of Energy and Mineral Development.

Valdés, A., and W. Foster. 2010. Reflections on the role of agriculture in pro-poor growth. World Development 38 (10): 1362-1374.

Wiebelt, M., K. Pauw, J. M. Matovu, E. Twimukye, and T. Benson. 2011. Managing future oil revenue for agricultural development and poverty reduction: A CGE analysis of challenges and options. IFPRI Discussion Paper 1122. Washington, DC: International Food Policy Research Institute.

World Bank. 2010. Country assistance strategy for the Republic of Uganda for the period FY 2011-2015. Washington, DC: World Bank.

Manfred Wiebelt is a Senior Research Fellow at the Kiel Institute for the World Economy, an Adjunct Professor of Economics at Kiel University, and Director of the Poverty Reduction, Equity and Growth Network (PEGNet). He holds a PhD in Economics from Heidelberg University. His research focuses on trade and agricultural policies, pro-poor growth, and management of natural resources, primarily based on empirical general equilibrium analysis with a focus on sub-Saharan Africa and the Middle East and North Africa.

Karl Pauw is the Regional Coordinator for the Monitoring and Analyzing Food and Agricultural Policies (MAFAP) program of the United Nations Food and Agriculture Organization (FAO), based in Addis Ababa, Ethiopia. At the time of writing his respective contributions in this book he was a Research Fellow at the International Food Policy Research Institute (IFPRI) and manager of IFPRI's Malawi country program in Lilongwe. He holds a PhD in development economics from the University of Cape Town, South Africa, and his research interests include: development and agricultural policy analysis; microeconomic analyses of labor markets, poverty, welfare outcomes, and nutrition; and policy impact analysis using computable general equilibrium and microsimulation models.

John Mary Matovu is a Senior Economist at Research for Transformation and Development, based in Uganda. Before he held posts at the International Monetary Fund, Washington, DC and at the Economic Policy Research Centre in Kampala. He obtained his $\mathrm{PhD}$ in Economics from Oxford University. His research focuses on the incidence of tax reforms, fiscal response to commodity price shocks, climate-change induced productivity shocks, and domestic resource mobilization in Uganda, primarily using computable general equilibrium models.

Evarist Twimukye at the time of writing this article, Everist Twimukye was a Senior Research Fellow at the Economic Policy Research Centre, based in Kampala, Uganda. He holds a PhD in Applied Economics from Clemson University, USA. His main areas of research and publication include growth and employment, financial economics, fiscal policy, foreign direct investment, food policy analysis, and trade and integration economics. 
Todd Benson is a Senior Research Fellow in the Development Strategy and Governance Division at the International Food Policy Research Institute, based in Washington, DC. He obtained his $\mathrm{PhD}$ in Geography from the University of Minnesota. His research focuses on policy analysis for poverty reduction, agricultural development, food security, and improved nutrition, primarily using microeconomic and spatial data sets with a focus on sub-Saharan Africa.

Open Access This chapter is licensed under the terms of the Creative Commons Attribution 4.0 International License (http://creativecommons.org/licenses/by/4.0/), which permits use, sharing, adaptation, distribution and reproduction in any medium or format, as long as you give appropriate credit to the original author(s) and the source, provide a link to the Creative Commons license and indicate if changes were made.

The images or other third party material in this chapter are included in the chapter's Creative Commons license, unless indicated otherwise in a credit line to the material. If material is not included in the chapter's Creative Commons license and your intended use is not permitted by statutory regulation or exceeds the permitted use, you will need to obtain permission directly from the copyright holder.

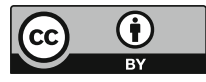

